\title{
A preliminary study on diabetes self-management education and glycemic control among patients with diabetes mellitus
}

\author{
Kisokanth G. ${ }^{* 1}$, Indrakumar J. ${ }^{2}$, Prathapan S. ${ }^{3}$, Joseph J. ${ }^{1}$, Ilankoon I.M.P.S. ${ }^{4}$ \\ ${ }^{1}$ Department of Supplementary Health Sciences, Faculty of Health-Care Sciences, Eastern University, Sri Lanka \\ ${ }^{2}$ Department of Medicine, Faculty of Medical Sciences, University of Sri Jayewardenepura, Sri Lanka \\ ${ }^{3}$ Department of Community Medicine, Faculty of Medical Sciences, University of Sri Jayewardenepura, Sri Lanka \\ ${ }^{4}$ Department of Nursing and Midwifery, Faculty of Allied Health Sciences, University of Sri Jayewardenepura, Sri Lanka
}

Received: January 18, 2019

DOI: $10.5430 /$ jnep.v9n9p98
Accepted: March 10, 2019

Online Published: June 20, 2019

\begin{abstract}
This study was aimed to assess the effectiveness of diabetes self-management education (DSME) in the improvement of glycemic control among patients with type 2 Diabetes Mellitus (T2DM) in Batticaloa District, Sri Lanka. The study was a prospective interventional study and conducted as a preliminary study at medical clinic, Base hospital, Kaluwanchikudy, Batticaloa. Thirty patients with T2DM were included based on inclusion and exclusion criteria. A structured individual diabetes self-management education for 10 hours (one hour per week) was delivered to diabetic patients by the trained Nurse Health Educator. Glycosylate hemoglobin (HbA1c) was assessed as a main outcome measure and Fasting Blood Sugar (FBS), Body Mass Index (BMI) of each patient were also measured and recorded before and after the intervention. The respondent rate was $96.7 \%(\mathrm{n}=29)$. Majority of them were females $(\mathrm{n}=25,86.2 \%)$. A Wilcoxon signed rank test showed that DSME had a statistically significant reduction in HbA1c [8.60 (IQR 2.60) vs. 7.40 (IQR 2.10), $p=.000]$ and FBS level [159.00 (IQR 77.50) vs. 134.00 (IQR 40.50), $p=.002]$ at 3 months of intervention. The mean BMI at baseline was higher compared to 3 months of intervention [24.88 (SD \pm 3.06$)$ vs. $24.19(\mathrm{SD} \pm 2.79)]$ which was statistically significant $(p=.000)$. Majority of participants $(\mathrm{n}=22,75.9 \%)$ had improved their HbA1c level by $\geq 0.5 \%$ in 3 months. The diabetes self-management education is an effective measure in improving glycemic control and other clinical parameters among patients with T2DM. Thus, DSME needs to be implemented among clinic patients with T2DM for the better outcome and the preventions of complications.
\end{abstract}

Key Words: Diabetes education, Self-management, Type 2 Diabetes Mellitus, Glycemic control

\section{INTRODUCTION}

Type 2 Diabetes Mellitus (T2DM) was considered as most common and worst non-communicable disease worldwide and associated with significant morbidity and mortality. ${ }^{[1]}$ The recent global report of WHO highlighted that the global prevalence of T2DM among adults over 18 years of age has risen from $4.7 \%$ in 1980 to $8.5 \%$ in $2014 . .^{[2]}$ Overall global prevalence of T2DM is expected to rise from $6.0 \%$ to $7.3 \%$ over the 18 years from 2007 to 2025 and an absolute increase from 246 to 380 million persons. ${ }^{[3]}$ Even though, all ethnic groups are affected, the prevalence of T2DM in South Asians is extremely high and is continuing to rise rapidly ${ }^{[4]}$ Further, T2DM accounts for $90 \%-95 \%$ of all patients with DM. ${ }^{[5]}$

\footnotetext{
*Correspondence: Kisokanth G.; Email: kiso.1983@yahoo.com; Address: Department of Supplementary Health Sciences, Faculty of Health-Care Sciences, Eastern University, Sri Lanka.
} 
T2DM is a serious chronic hyperglycaemia condition, and its prevalence is increasing globally ${ }^{[6]}$ as well as in Sri Lanka. ${ }^{[7,8]}$ The urbanization and industrialization have led to sedentary life, physical inactivity, stress and obesity among T2DM. ${ }^{[9]}$ According to International Diabetes Federation (IDF), one in 11 adults has DM and one in 2 adults with DM undiagnosed worldwide. ${ }^{[10]}$

$\mathrm{DM}$ is a condition that, if uncontrolled can produce lifelong complications affecting different organs of the body such as kidney, eye, and feet. ${ }^{[11]}$ Complications of DM are physiologically harmful, and are costly for both the patients and the government. ${ }^{[12]}$ T2DM is the 14 th largest cause of disability adjusted life years (DALYs) worldwide and 16th highest in South Asia. ${ }^{[13]}$

T2DM is increasing in prevalence and is seen more and more among the young adults in Sri Lanka. The direct and indirect health care expenditure and economic impact of T2DM and its complications is expected to be exponential in Sri Lanka. ${ }^{[14]}$ Lack of knowledge regarding T2DM and its complications among diabetic patients is a health issue. Patients are not sufficiently equipped with knowledge to comprehensively manage their disease ${ }^{[15]}$ and there is an urgent need for strategies to spread awareness about T2DM in diabetic patients. ${ }^{[16]}$

The optimal glycemic control has a significant decrease in the development of complications of T2DM. ${ }^{[17]}$ Further, poor glycemic control can cause a number of socioeconomic consequences in individual, families, society and healthcare systems. ${ }^{[18]}$ Knowledge of disease can thus prevent the impending chronic co-morbidities for T2DM, which impact significantly on the quality of life of the diabetic patients. ${ }^{[15]}$ Thus, appropriate diabetes health education would helping early recognition of symptoms and allow for prompt treatment. ${ }^{[19]}$

T2DM proper management depends on self-management education which is the key component of diabetic care. ${ }^{[20]}$ Diabetes education is of paramount importance in its selfmanagement. ${ }^{[6]}$ It provides the knowledge and skills needed to perform self-care, manage the crisis and to make lifestyle changes for successful glycemic control. Diabetes Selfmanagement Education (DSME) programme facilitates in acquisition of preventive or therapeutic self- care activities among patients in collaboration with health care providers. The overall objectives of DSME are to support informed decision making, problem solving and change in behavior. The fundamental outcome of DSME is to change the behavior of the patients for necessary expected outcome.

Even though, DSME is aimed to fill the needed gaps in the im- provement of glycemic control among patients with T2DM and shown to be effective in glycemic control, there is a severe shortage of trained diabetes educators in Sri Lanka. ${ }^{[21]}$ Further, Diabetic care is seriously concern in hospital based management, there is no obvious well-structured continuous DSME facilities organised in the health care context in Sri Lanka. Therefore, the study was aimed to assess the effectiveness of DSME in the improvement of glycemic control among patients with T2DM first time in a selected hospital, Batticaloa District, Sri Lanka as a preliminary study.

\section{Methodology}

Single group, pre- and post-test research designs was used to assess the effectiveness of DSME in the improvement of glycemic control among patients with T2DM attending the medical clinic, Base Hospital, Kaluwanchikudy, Sri Lanka as a pilot study during January - April 2016. This Single group, pre- and post-test research designs evaluate causal relationships between intervention and outcome. ${ }^{[22]}$ The participants included in this study were patients who have lived at least for 2 years in the Kaluwanchikudy area with T2DM, diagnosed at least 2 years ago, treated with oral hypoglycemic agents or insulin or both or diet alone and age of above 30 years. Patients who refused to consent for participating in the study, patients with Gestational Diabetes Mellitus (GDM), patients having any physical discomfort or pain due to surgery or ulcers (crossed checked with clinic record book) and who refused to attend weekly health education session were excluded from the study. The study period was about three months. All included patients were seen monthly by medical officer at the clinic.

A single group of thirty (30) patients with T2DM were randomly selected and DSME was delivered individually at medical clinic, Base Hospital, Kaluwanchikudy. When estimating the sample size for the pilot study, the simplest method was applied as rules of thumb. ${ }^{[23]}$ Browne (1995) cites a general flat rule to 'use at least 30 subjects or greater to estimate a parameter for a pilot study, ${ }^{[24]}$ whereas Kieser and Wassmer (1996) recommend a pilot trial sample size between 20 and 40. ${ }^{[25]}$ The education team consisted of a consultant physician, a community consultant physician and a trained nurse health educator (Principal investigator). The program consisted of one hour 10 weekly education sessions. DSME was delivered using validated intervention guide (Annexure I and II). Each DSME session was structured into three phases: 1) Introduction to T2DM (theoretical aspects of T2DM) which includes pathophysiology of T2DM, awareness and treatment of hypoglycaemia and hyperglycaemia, complications of T2DM; 2) Lifestyle modification instructions which include instructions on diet, physical activity, 
medication, self-monitoring and stress management; 3) Selfcare activities especially on foot care. All individual patients were seen by the same education team, in the same offices and according to the same procedure.

Before delivering DSME to the study sample, baseline glycosylate hemoglobin (HbA1c), Fasting blood sugar (FBS) and body mass index (BMI) were measured and recorded by trained research assistant 1 . An interviewer administered questionnaire was used to obtain the socio-demographic details of participants. After completion of 10 weeks (nearly at 3 months), HbA1c, BMI and FBS were again measured and recorded by trained research assistant 2 to avoid the contamination.

The software SPSS v.20 was used for all statistical analysis. Descriptive characteristics of the study patients were calculated as means \pm standard deviations (SD) for continuous variables and as percentages for categorical variables. Overall improvement was assessed on a primary outcome (HbA1c) and secondary outcomes (FBS and BMI) between baseline and after 3 months of intervention by using a paired $t$-test or Wilcoxon signed-rank test based on normality distribution of the differences between the two related groups. The $p$ value $<.05$ was considered statistically significant.

The ethical approval (ERC No: 627/12) was obtained from Ethic Review Committee, Faculty of Medical Sciences, University of Sri Jayewardenepura, Sri Lanka. The permission was obtained from the Medical Superintend, Base hospital, Kaluwanchikudy prior to the study. The study procedure was explained in details and written informed consent was obtained from all participants. Data obtained were kept under lock and key. Privacy, confidentiality and anonymity of the subjects were ensured throughout the study. Accessibility to all the data collected was limited to the investigators only.

\section{RESULTS AND DISCUSSION}

The current study examined the effectiveness of selfmanagement health education on diabetes care for glycaemic control. The effectiveness of intervention was assessed by the primary outcome of HbA1c. The United Kingdom Prospective Diabetes Study (UKPDS) revealed that HbA1c is being used as the most reliable test of assessing glycemic control and risk of complications. ${ }^{[26]}$

According to Wagner, et al. (2001), diabetes selfmanagement education is an important strategy for good glycemic control where patients receive periodic health education session to meet their needs. ${ }^{[27]}$ In order to improve the primary outcome of HbA1c in self-management of T2DM, the patient education becomes an integral part ${ }^{[28]}$ which provides adequate knowledge on disease aspects and selfmanagement strategies.

In the present study, a total of 30 patients was included and 1 patient dropped out. The respondent rate was $96.7 \%(\mathrm{n}=$ 29). Majority of them were females $(n=25,86.2 \%)$. Majority of the sociodemographic factors showed no statistically significant difference between male and female $(p>.05)$ (see Table 1).

Table 1. Socio-demographic characteristics of participants based on gender differences

\begin{tabular}{|c|c|c|c|c|c|}
\hline Characteristic & Response & $\begin{array}{l}\text { Male } \\
\text { n (\%) }\end{array}$ & $\begin{array}{l}\text { Female } \\
\text { n (\%) }\end{array}$ & $\begin{array}{l}\text { Total } \\
\text { n (\%) }\end{array}$ & $p$ value \\
\hline Gender & & $4(13.8)$ & $25(86.2)$ & $29(100.0)$ & - \\
\hline \multirow{2}{*}{ Age group (years) } & $31-50$ & $2(50.0)$ & $18(72.0)$ & $20(69.0)$ & \multirow{2}{*}{.37} \\
\hline & $51-70$ & $2(50.0)$ & $7(28.0)$ & $9(31.0)$ & \\
\hline \multirow{2}{*}{ Ethnic Background } & Tamil & $4(100.0)$ & $19(76.0)$ & $23(79.3)$ & \multirow{2}{*}{.27} \\
\hline & Burger & $0(0.0)$ & $6(24.0)$ & $6(20.7)$ & \\
\hline \multirow{4}{*}{ Educational level } & Never attend to School & $0(0.0)$ & $3(12.0)$ & $3(10.3)$ & \multirow{4}{*}{.32} \\
\hline & Primary & $2(50.0)$ & $8(32.0)$ & $10(34.5)$ & \\
\hline & Upto GCE (O/L) & $1(25.0)$ & $13(52.0)$ & $14(48.3)$ & \\
\hline & Upto GCE (A/L) and above & $1(25.0)$ & $1(4.0)$ & $2(6.9)$ & \\
\hline \multirow{4}{*}{ Monthly income (Rs) } & $<10,000$ & $1(25.0)$ & $4(16.0)$ & $5(17.2)$ & \multirow{4}{*}{.52} \\
\hline & $10,000-24,999$ & $2(50.0)$ & $12(48.0)$ & $14(48.3)$ & \\
\hline & $25,000-39,999$ & $0(0.0)$ & $7(28.0)$ & $7(24.2)$ & \\
\hline & $\geq 40,000$ & $1(25.0)$ & $2(8.0)$ & $3(10.3)$ & \\
\hline \multirow{4}{*}{ Marital status } & Single & $1(25.0)$ & $1(4.0)$ & $2(6.9)$ & \multirow{4}{*}{.01} \\
\hline & Married & $1(25.0)$ & $22(88.0)$ & $23(79.3)$ & \\
\hline & Divorced/Separated & $0(0.0)$ & $1(4.0)$ & $1(3.4)$ & \\
\hline & Widowed & $2(50.0)$ & $1(4.0)$ & $3(10.4)$ & \\
\hline \multirow{3}{*}{ Duration of DM (years) } & $2.0-5.0$ & $1(25.0)$ & $6(24.0)$ & $7(24.1)$ & \multirow{3}{*}{.89} \\
\hline & $5.1-10.0$ & $2(50.0)$ & $15(60.0)$ & $17(58.6)$ & \\
\hline & $>10.0$ & $1(25.0)$ & $4(16.0)$ & $5(17.3)$ & \\
\hline
\end{tabular}

Note. GCE (O/L) - General Certificate of Education (Ordinary Level), GEC (A/L) - General Certificate of Education (Advanced level) 
Overall improvement of primary and secondary outcome

A Wilcoxon signed rank test showed that intervention group had a statistically significant changes in HbA1c and FBS level at 3 months of intervention. Further, the mean BMI at baseline was higher compared to 3 months of interven- tion $\left[24.88 \mathrm{Kg} / \mathrm{m}^{2}(\mathrm{SD} \pm 3.06)\right.$ vs. $24.19 \mathrm{Kg} / \mathrm{m}^{2}(\mathrm{SD} \pm$ 2.79)] which was statistically significant $(p=.000)$ (see Table 2). Further, majority of participants $(\mathrm{n}=22,75.9 \%)$ had improved their $\mathrm{HbAlc}$ level by $\geq 0.5 \%$ in 3 months of intervention (see Table 3).

Table 2. Mean/median of primary and secondary outcome variables between baseline and after 3 months of intervention

\begin{tabular}{lllll}
\hline Variables & $\begin{array}{l}\text { Baseline } \\
(\mathbf{n}=\mathbf{2 9})\end{array}$ & $\begin{array}{l}\text { After 3 months } \\
(\mathbf{n = 2 9 )}\end{array}$ & $\begin{array}{l}\text { Mean/median } \\
\text { difference }\end{array}$ & $\boldsymbol{p}$ value \\
\hline HbA1c $(\%)^{¥}$ & $8.60(2.60)$ & $7.40(2.10)$ & $1.00(1.35)$ & $.000^{@}$ \\
FBS $(\mathrm{mg} / \mathrm{dl})^{\ddagger}$ & $159.00(77.50)$ & $134.00(40.50)$ & $17.00(52.00)$ & $.002^{@}$ \\
BMI $\left(\mathrm{Kg} / \mathrm{m}^{2}\right)^{\infty}$ & $24.88(3.06)$ & $24.19(2.79)$ & $0.69(0.70)$ & $.000^{\dagger}$ \\
\hline
\end{tabular}

Note. @ - Wilcoxon Signed Ranks Test, $\uparrow$-Paired $t$-test, $\infty$ - Variable outcomes are shown as mean with \pm SD (standard deviation), $¥$-Variable outcomes are shown as median with IQR (Interquartile range).

Table 3. Overall HbA1c improvement among all participants

\begin{tabular}{ll}
\hline HbA1c improvement & Participants (n, \%) \\
\hline $0.4 \%$ & $07(24.1)$ \\
$0.5-1.0 \%$ & $08(27.6)$ \\
$1.1 \%-1.5 \%$ & $06(20.7)$ \\
$>1.5 \%$ & $08(27.6)$ \\
\hline
\end{tabular}

On implementation of DSME, the level of HbA1c was significantly reduced in the study participants by $1.33 \%( \pm 1.57)$ in 3 months. The mean HbA1c level of $8.91 \%( \pm 2.22)$ at pre-interventional level was declined to $7.58 \%( \pm 1.36)$ at the end of 3 months of intervention. Further, nearly $76 \%$ of participants had improved their HbA1c level by $\geq 0.5 \%$. In addition, FBS and BMI were also reduced significantly in study participants. This shows that study participants were able to reach the target $\mathrm{HbA} 1 \mathrm{c}$ level of $\leq 7.0 \%$ of Sri Lanka. ${ }^{[29]}$ Further, it revealed that DSME had led to significant improvement in self-management of DM among patients in relation to glycemic improvement by adaptation on self-management activities such as appropriate diet, regular exercise, appropriate use of medications and regular follow-up.

Similarly, it has been found in several studies that the minimum significant reduction of $\mathrm{HbA1C}$ level was observed as $0.5 \%$ due to self-management education intervention. ${ }^{[30,31]}$ A systematic review on effect of health education on selfmonitoring of blood glucose found that intervention would improve metabolic control with a decrease of $0.5 \%$ or more in HbA1c level. ${ }^{[30]}$ In addition, a Randomized control trail focused on diabetes health education regarding selfmanagement behaviors shows that individual education led to reductions in $\mathrm{HbA} 1 \mathrm{c}$ levels of $0.5 \%$ that were not observed

Published by Sciedu Press in the group-based education and usual care groups. ${ }^{[31]}$

Based on the results, the intervention has helped the patient to be independent with regards to self-management of DM. In addition, it could be reasonably stated that such kind of intervention of DSME among diabetic patients was not a common way of health provider - patient communication in our country which indeed has resulted good effects. Accordingly, significant improvement $(p<.05)$ in glycemic control (HbA1c, FBS) and other outcomes (BMI) are achievable with DSME in this study.

\section{Limitations}

Change in self-care behaviors of patients with DM due to intervention was not measured objectively as it difficult to assess the human behaviors and it would be self-reported, and therefore the outcomes were measured as an impact of selfcare behaviors. Also, female participants were high among all study participants which would be bias to the study.

\section{Conclusion}

Diabetes self-management education programs followed in clinic set-up in a hospital is an effective approach in improving glycemic control and other clinical parameters such as BMI and FBS among diabetic patients as evidenced by this study. Thus, diabetes self-management education programs in large scale needs to be implemented to assess its effectiveness for better glycemic control.

\section{FUNDING}

Authors wish to extend their gratitude to University of Sri Jayewardenapura, Sri Lanka (Grant No ASP/01/RE/MED/2016/62) for providing me financial assistance to carry out and complete the study. 


\section{ACKNOWLEDGements}

The authors would like to thank all patients who participated in this study. Also, we express our gratitude to Medical Superintend, Base Hospital, Kaluwanchikudy and other staff who provided their fullest support to complete this study successfully.

\section{Conflicts of Interest Disclosure}

The authors declares that there is no conflict of interest.

\section{REFERENCES}

[1] Siyambalapitiya S, Gunathilake G, Perera I. Exercise: an essential component of diabetes management. Sri Lanka Journal of Diabetes Endocrinology and Metabolism. 2012; 2(2): 57-60. https: //doi.org/10.4038/sjdem.v2i2.4773

[2] World Health Organization, 2016. Global report on diabetes. Available from: http://apps.who.int/iris/bitstream/10665/ 204871/1/9789241565257_eng.pdf

[3] Bilous R, Donnelly R. Handbook of Diabetes. 4th ed. Excerpt 6: Epidemiology and Aetiology of Type 2 Diabetes. A John Wiley \& Sons, Ltd. Publication; 2014.

[4] Gujral UP, Pradeepa R, Weber MB, et al. Type 2 diabetes in South Asians: similarities and differences with white Caucasian and other populations. Annals of the New York Academy of Sciences. 2013; 1281(1): 51-63. PMid:23317344 https://doi.org/10.1111/j. 1749-6632.2012.06838.x

[5] American Diabetes Association, 2017a. Standards of medical care in diabetes: Classification and diagnosis of diabetes. Diabetes Care. 2017; 40(Suppl. 1): S11-S24. PMid:27979889 https://doi.org/ $10.2337 /$ dc17-S005

[6] Khunti K, et al. Effectiveness of a diabetes education and self management programme (DESMOND) for people with newly diagnosed type 2 diabetes mellitus: three year follow-up of a cluster randomised controlled trial in primary care. BMJ. 2012; 344: e2333. PMid:22539172 https://doi.org/10.1136/bmj.e2333

[7] Wijewardene K, Mohideen MR, Mendis S, et al. Prevalence of hypertension, diabetes and obesity: baseline findings of a population based survey in four provinces in Sri Lanka. Ceylon Medical Journal. 2005; 50(2): 62-70. PMid:16114771 https://doi.org/10.4038/cmj v50i2.1571

[8] Amarasinghe S, Balakumar S, Arasaratnam V. Prevalence and risk factors of diabetes mellitus among adults in Jaffna District. Ceylon Med. Journal. 2015; 60(3): 107-110. PMid:26520866 https: //doi.org/10.4038/cmj.v60i3.8191

[9] Wijesuriya MA. Prevalence of Diabetes in Sri Lanka. Ceylon Medical Journal. 1997; 17(1): 1-4.

[10] International Diabetes Federation. IDF Diabetes Atlas-Seventh Edition. Available from: https://www.idf.org/diabetesatlas

[11] Smeltzer SC, Bare BG, Hinkle JL, et al. Brunner and Suddarth's Textbook of Medical Surgical Nursing, 12th ed. Lippincott; Williams - Wilkins; 2009.

[12] AlShafaee MA, AlShukaili S, Rizvi SGA, et al. Knowledge and perceptions of Diabetes in a semi-urban Omani population. Biomed Central Public Health. 2008; 8: 249. PMid:18644163 https : //do i. org/10.1186/1471-2458-8-249

[13] Bhutani J, Bhutani S. Worldwide burden of diabetes. Indian Journal of Endocrinology and Metabolism. 2014; 18(6): 868-870. PMid:25364686 https://doi.org/10.4103/2230-8210.1413 88

[14] Ranasinghe P, Pigera ASAD, Ishara MH, et al. Knowledge and perceptions about diet and physical activity among Sri Lankan adults with diabetes mellitus: a qualitative study. BMC Public Health. 2015; 1160. PMid:26597081 https://doi.org/10.1186/s12889-015 $-2518-3$

[15] Moodley LM, Rambiritch V. An assessment of the level of knowledge about diabetes mellitus among diabetic patients in a primary healthcare setting. South African Family Practice Journal. 2007; 49(10): 16. https://doi.org/10.1080/20786204.2007.10873652

[16] Murugesan N, Shehalatha C, Shobana R, et al. Awareness about diabetes in the general and diabetic population in a city in southern India. Journal of Diabetes Research and Clinic Practice. 2007; 77(3): 433-437. PMid:17291622 https ://doi.org/10.1016/j. diabres.2007.01.004

[17] Stratton IM, Adler AI, Neil HA, et al. Association of glycemia with macrovascular and microvascular complications of type 2 diabetes (UKPDS 35): prospective observational study. BMJ. 2000; 321: 405412. PMid:10938048 https://doi.org/10.1136/bmj . 321.72 58.405

[18] Davies MJ, D'Alessio DA, Fradkin J, et al. Management of hyperglycemia in type 2 diabetes. A consensus report by the American Diabetes Association (ADA) and the European Association for the Study of Diabetes (EASD). Diabetes Care. 2018; 41: 2669-2701. PMid:30291106 https://doi.org/10.2337/dci18-0033

[19] Wee HL, Ho HK, Li SC. Public Awareness of Diabetes Mellitus in Singapore. Singapore Medical Journal. 2002; 43(3): 128-134.

[20] Mensing C, Boucher J, Cypress M, et al. National Standards for Diabetes Self-Management Education. Diabetes Care. 2002; 25: 140-147. https://doi.org/10.2337/diacare.25.2007.S140

[21] Illangasekera $U$. Towards a cost-effective delivery of diabetes care in Sri Lanka. Sri Lanka Journal of Diabetes Endocrinology and Metabolism. 2011; 1: 55-57. https://doi.org/10.4038/sjdem. v1i1.4210

[22] Marsden E, Torgerson CJ. Single group, pre- and post-test research designs: Some methodological concerns. Oxford Review of Education. 2012; 38(5): 583-616. https://doi .org/10.1080/030549 85.2012.731208

[23] Whitehead AL, Julious SA, Cooper CL, et al. Estimating the sample size for a pilot randomised trial to minimise the overall trial sample size for the external pilot and main trial for a continuous outcome variable. Statistical Methods in Medical Research. 2016; 25(3): 10571073. PMid:26092476 https://doi.org/10.1177/0962280215 588241

[24] Browne RH. On the use of a pilot sample for sample size determination. Stat Med. 1995; 14: 1933-1940. https ://doi.org/10.100 2/sim. 4780141709

[25] Kieser M, Wassmer G. On the use of the upper confidence limit for the variance from a pilot sample for sample size determination. Biom J. 1996; 8: 941-949. https://doi.org/10.1002/bimj. 47103 80806

[26] United Kingdom Prospective Diabetes Study (UKPDS) Group. Intensive blood-glucose control with sulphonylureas or insulin compared with conventional treatment and risk of complications in patients 
with type 2 diabetes (UKPDS 33). Lancet. 1998; 352(9131): 837853. https://doi.org/10.1016/S0140-6736(98)07019-6

[27] Wagner EH, Glasgow RE, Davis C, et al. Quality improvement in chronic illness care: a collaborative approach. Jt Comm J Qual Improv. 2001; 27(2): 63-80. https://doi.org/10.1016/S1070-3 241 (01) $27007-2$

[28] NICE guideline. UK, Type 2 diabetes in adults: management. Available from: https://www.nice.org.uk/Guidance/NG28

[29] Somasundaram NP, Wijeyaratne CN, De Silva S, et al. Diabetes Mellitus: Glucose Control. Sri Lanka Journal of Diabetes Endocrinology and Metabolism. 2013; 3(1): 45-57. https://doi.org/10.4038/ sjdem.v3i1.5505

[30] Clar C, Barnard K, Cummins E, et al. Self-monitoring of blood glucose in type 2 diabetes: systematic review. Health Technology Assessment. 2010; 14(12). https://doi .org/10.3310/hta14120

[31] Sperl-Hillen J, Beaton S, Fernandes O, et al. Comparative effectiveness of patient education methods for type 2 diabetes: a randomized controlled trial. Arch Intern Med. 2011; 171(22): 2001 2010. PMid:21986350 https://doi.org/10.1001/archintern med. 2011.507 